\title{
The problem of reductionism in educational theory: complexity, causality, values
}

\begin{abstract}
This paper seeks to examine some of the problems in current policy, pedagogy and practice through the concept of 'reductionism'. It examines various forms which this may take involving inappropriate scientific methodologies, a diminished sense of structure (or conversely, agency), temporal confusion, and teleological / ethical reductionism, drawing on examples from natural and social sciences as well as education. It draws on Critical Realist understandings of causality, stratification and emergence to ground the discussion ontologically and epistemologically. The article then builds on this theoretical foundation for a critical discussion of teaching and learning, poverty-related underachievement, school development, and evidence-based teaching.
\end{abstract}

\section{Keywords}

reductionism, stratification, emergence, Critical Realism, educational aims

\section{Introduction}

This article draws on the concept of reductionism to examine inadequate theorisation and mechanistic causal assumptions in education, which result in a loss of complexity, openness and values. This seems particularly appropriate at present for England and similar systems, where reductionist approaches have become hegemonic in many aspects of schooling. In recent years a strident ideological campaign, led by government ministers, has sought to reconceptualise and reconfigure what counts as educational achievement, high quality teaching, social justice and research evidence. This involves not only the depoliticisation of politics and policy (Harvey 2010:218-9) but but also a shift towards a technical discourse when considering curricular and pedagogical issues and practices (Shapiro 1990:13; Clarke 2012).

A critique of reductionism is important, therefore, to protect against misleading simplifications. Although the concept is relatively familiar in the natural and social sciences (see Bock and Goode 1998, Sayer 2010) it has rarely been highlighted in the field of education, where its use has generally either been applied to very specific issues or used as a vague term of abuse. (Some honourable but rare exceptions are referred to below eg Apple 1984; Beck 2007.) For that reason, this article attempts to map different forms of reductionism, drawing on debates in natural and social sciences. Further, to ground this in a coherent ontology and epistemology, it refers to theories of causality, stratification and emergence in Critical Realism. It moves on to reflect on important manifestations of reductionism in education, involving pedagogical theory, poverty and underachievement, school evaluation and change, and evidence-based practice. 
Reductionism affects policy and administrative systems as well as related research paradigms, but goes right down to fundamental assumptions about learning and knowledge. In practical terms, reductionism is disempowering because it denies to professionals, as well as policy makers, the understanding they need to operate skilfully and with agency in challenging situations.

Reductionism, in various forms, depends too much on surface readings of reality, reinforcing 'common sense' assumptions. It obscures, distorts or simply fails to perceive the power dimension of what it studies. This results in ideological misrepresentation which disempowers practitioners.

\section{The concept of reductionism}

Reductionism takes many forms but generally signifies a loss of complexity which hinders an adequate understanding of reality. In its classic usage, it refers to the inappropriate deployment of one scientific discipline to explain matters which require a different branch of science. This is described, metaphorically, as using too 'low' a science, for example trying to explain biological phenomena mainly through chemistry, or complex social situations such as war in terms of aggressive animal instincts.

Reductionism is not however limited to this idea of a 'hierarchy' of sciences. More generally, it can also refer to the 'omission of important co-determinants of a multi-causal situation' (Sayer (2010:34), or the choice of an inappropriate perspective or conceptual framework. It is for this reason that Rose (2005:95) insists on ontological unity but epistemological pluralism. Using the example of a frog jumping into a pond (ibid:100-13), it is perfectly valid to study the biochemical properties of its muscles but this will not explain why now. Its reaction to a nearby snake requires other explanations including intellligent evasion or instinctive reactions rewarded by natural selection. The argument goes back a long way, indeed it is prefigured by Aristotle's model of four complementary types of causality: material, formal, efficient and final causes. Drawing on and moving beyond Sayer (2010), I will attempt in this section to map out various directions which reductionism can take.

It may be, however, that we are also dealing with something in the Zeitgeist - a certain haste in finding fast answers and quick policy fixes, along with the eclipsing of philosophical discussion in public life. Daniel Dennett (1995:82) speaks of a 'greedy reductionism':

In their eagerness for a bargain, in their zeal to explain too much too fast, scientists and philosophers... underestimate the complexities, trying to skip whole layers or levels of theory in their rush to fasten everything securely and neatly to the foundation.

\section{Scientific stratification}


a) The problem here involves explaining phenomena through too 'low' a science. Sayer (2010:5) presents the metaphor of various 'layers', starting at the 'bottom' with the physical, then the chemical, biological, and finally the social. (He leaves open the possibility that the psychological sits at a different 'level' to the social.) The 'lower' explanations cannot be ignored: for example, biological powers are dependent on but irreducible to physical and chemical laws.

It has become commonplace to argue that the dominance of physics ended with a 20th Century crisis in that discipline such as the uncertainty principle. However the need to differentiation the fundamental principles of different sciences came much earlier. Prigogine and Stengers (2017) trace the first challenge to Newtonian physics to advances in chemistry in the late 18th Century. Writing towards the end of the 19th Century, Friedrich Engels points to Hegel's early grasp of qualitative differences between 'mechanics, chemics and organics' [Engels 1964:253, also note 203]. Engels recognises that Newtonian physics deals with movements between solid objects, whereas chemistry deals with the internal changes of matter. A major transformation occurs with life, whereby chemical processes involving proteins become 'a self-acting, permanent chemical process' (ibid:259). He remarks on the development of structures from which new levels of activity emerge:

Vertebrates. Their essential character: the grouping of the whole body about the nervous system. Thereby the development of self-consciousness, etc., becomes possible. (ibid:314) Engels has a clear understanding of emergence in nature, traced by the development of the higher sciences, and that the lower sciences still apply to living things, but also directly highlights the dangers of reductionism:

One day we shall certainly "reduce" thought experimentally to molecular and chemical motions in the brain; but does that exhaust the essence of thought? (ibid:251)

All of this is a long way from the caricatures of Marxism as mechanistic materialism, found in postmodernist and 'new materialist' writings, and this understanding of the dynamic complexity of the natural world provides a basis for challenging reductionism in the field of education.

b) The reverse can also be a problem, i.e. the danger of trying to explain an event or change through psychological or cultural factors alone without considering material or economic issues. Sayer (2010:6) calls this 'upward reduction', including the idea that 'everything is cultural' or discursive, or explaining public events entirely through psychological motivations or individual desires. He critiques interpretivism as a 'tendency to reduce social life wholly to the level of meaning, ignoring material change and what happens to people, regardless of their understandings' (Sayer 2000:56). There is no one-to-one correspondence between the biological and the social or psychological but we cannot simply 'write out nature' (Sayer 2000:98). 


\section{Scalar reductionism}

I am using this broad heading to describe explanations which focus excessively on either proximal or distal factors. However it is not only a matter of physical distance, as it also considers explanations which overemphasise either structure or agency. This is a particular mode of what Sayer (2010:6) calls reducing 'the explanations of multiply-determined processes to a few elements, ignoring others within the same stratum'.

c) A common problem in the contemporary politics of education is individualist explanation which pays scant attention to social structures, and which conveniently 'attributes to individuals sole responsibility for their fates' (Sayer 2010:7). We can see this acutely in Conservative explanations of poverty, as well as their emphasis on individual 'social mobility' (Littler 2018). A further example, on a larger scale (meso without macro), is looking within a situation and not beyond, for example School Improvement studies which look at a school in isolation without paying attention to the effects of the wider policy framework, economic pressures or social environment, and which can lead to 'no excuses' evaluations of school attainment data.

This is clearly not just a matter of spatial relations, but is reflected by longstanding disagreements in sociology about the relationship between structure and agency. Although structure often works through individuals, individual action cannot be understand without reference to large-scale structures: as Bhaskar (1979:35) expresses it, 'a tribesman implies a tribe, the cashing of a cheque a banking system'. 'The social structure... is always already made' but conversely social structures and forces are changed by individual agency (ibid:42seq). Developing this further, Archer points to the importance of time scale: structures 'pre-date any particular cohort of occupants / encumbants... agency does not create structure, but only reproduces or transforms it' (Archer 1995: 168). Structure is not always distinguished from agency on the basis of scale: key features of social structure and context are 'so to speak, built into the individual' (Lukes 1968:125).

d) The opposite mistake is a failure to look at particulars. This takes various forms, from overgeneralisation to sociological determinism. It also occurs when key words reify complex patterns and agglomerate a wide range of meanings (Rose 2005: 280); good examples in education might be 'leadership' or 'disadvantage'. The neglect of specificity or context reflects a failure to recognise that social situations (like most natural ones) are open systems, where multiple forces are at work which can contradict as well as reinforce each other (Bhaskar 1978:1979). Moreover, in social situations we also need to consider individual agency.

This argument has implications for theorising, as the process of abstraction implicitly involves removing complexity in favour of a clear identification of key forces. It suggests a need to rebuild complexity after any stage of abstraction, theorisation, modelling or experimentation. 


\section{Temporal reductionism}

e) Treating situations as if they were closed (standardised, predictably regular, mechanistic etc.) can close our eyes to emergence. The multiple factors involved do not simply combine additively, but can result in exponential or qualitative change. As Sayer (2010:14-15) explains:

Where the interaction of objects produces changes in the structure, powers, and susceptibililties of those objects, it can prompt the development of emergent powers powers not independently or merely additively possessed by those objects.

Neglect of the temporal dimension also involves a failure to take account of the weight of history. As Bhaskar points out, the social structure is 'always already made'. Although people reproduce, modify or transform it, they do not create it (1979:42). Moreover, the meaning systems through which we view the world (language, discourse, visual aesthetics, ideologies, imaginaries) are inherited from the past. A further danger is the smoothing out of historical processes by underplaying contradictions. Good examples in education can be found in John Beck's (2007) challenge to Stephen Ball's analysis of 'middle class' competitiveness in educational markets, or Michael Apple's (1984) critique of the kind of mechanistic marxism which tries to match educational situations rigidly to class structures.

\section{Teleological and ethical reductionism}

Human activity is permeated with a sense of purpose, and activities which lack it are described as alienated. That is not to say, however, that agents are always conscious of the significance of their actions, some of which are embodied habitus (eg Bourdieu 1977). However teleological reduction has become common in the field of education, and endemic in managerialist accounts of 'leadership', high-stakes accountability, and much statistically based research including evidencebased teaching. In all of these, there is a tendency for aims to be taken as read, or for output data to be regarded as itself an aim (X 2013a).

This inevitably leads into the question of values. Sayer (2010:28seq) argues against the dualism between 'fact' or 'reason' and 'values' in much social science, and suggests this results in the 'derationalization of values and the devaluation of reason'. The 'attempted expulsion over the last two centuries of values from social science' has resulted in the displacement ('ghettoization') of normative thought into moral and political philosophy (p29; see also Flyvbjerg 2001.) The desire to appear 'scientific' makes teleological reductionism more likely, given that the development of modern science required human purpose to be put out of the frame in the interest of objectivity. There is an alignment too with the wider political culture examined by Harvey (2010) who speaks of 'an astonishing pepriod in which politics has been depoliticised and commodified'. 


\section{The critical realist challenge: causality, stratification, emergence}

The preceding section has looked at various types of reductionist simplification, resulting in inadequate understandings of reality. This section aims to develop and deepen the argument by contrasting Critical Realist approaches to ontology and epistemology with an empiricism derived ultimately from David Hume. Although Humean empiricism is often tacit and unacknowledged, it is inherent in much experimental and statistical work in education and other social sciences. The critique of empiricism is not, of course, an argument against the need to empirically test out theories, or an invitation to engage in anti-realist or anti-materialist belief systems, but rather a challenge to inadequate versions of materialism or realism.

The empiricist error begins with Hume's sceptical argument that however many times one billiard ball hits another and the second ball moves, we still cannot assert a causal relationship. In other words, scientific laws can only express regularity, since we cannot get hold of the causal mechanism. Critical realists such as Bhaskar (1978) turn this round by distinguishing (1) the real, (2) the actual, and (3) the phenomenal. They argue that causal forces (the real) do not always actualise, and even when they do they may not be easily visible.

Causal laws must be analysed as tendencies, which may be possessed unexercised and exercised unrealized, just as they may of course be realized unperceived (or undetected) by anyone. (Bhaskar 2011:16)

In open systems, forces may be real (level 1), and formulable as scientific laws, without resulting in regularity (levels 2 and 3), since other forces are at work or the environment is unconducive.

Critical Realism, as a meta-theory of both natural and social reality - and consequently natural and social sciences - directly challenges the Humean emphasis on regularity. In Sayer's words:

The conventional impulse to prove causation by gathering data on regularities, repeated occurrences, is therefore misguided: at best these might suggest where to look for candidates for causal mechanisms. What causes something to happen has nothing to do with the number of times we observe it happening. (Sayer 2000:14)

Consequently the purpose of experiments is to artificially simplify and close situations in order to make a particular relationship more visible. Experiments are designed to stabilise other mechanisms or forces in order to highlight the impact of the dependent and independent variable chosen for investigation. Reductionism becomes a danger when the experiment is assumed to mirror reality, rather than being a simplified model of particular aspects. (The implications for quasi-experiments such as RCTs is discussed later.) Biologist Steven Rose explains that: 
Effective experiments demand the artificial controls imposed by the reductive methodology of the experimenter, but we must never forget that as a consequence they provide at best only a very simplified model, perhaps even a false one, of what happens in the blooming, buzzing, interactive confusion of life at large, where things rather rarely happen one at a time. $(2005: 28)$

Further:

What happens in the test-tube may be the same, the opposite of, or bear no relationship at all to what happens in the living cell, still less the living organism in its environment..

Reductionism is not enough when I come to try to interpret my own experiments. (p79) This presents a dilemma for scientists which Stephen Rose and Hilary Rose (1976:96) resolve as follows:

Reductionism as an experimental approach has been at the heart of the scientific method ever since the emergence of modern physics with Galileo and Newton. As an experimental method, reductionism is merely a procedure for explaining the properties of simplified, model systems, of holding all parameters except one constant, and varying that systematically.... Problems only arise when the tool is elevated into a philosophical principle, so that it is ignored that, for a complete explanation of an event or a process, it must be taken out of the vacuum into which reductionism plunges it and replaced in the bustle of the real world with which it is, in actuality, in constant interaction.

As well as openness, an understanding of the complexity of the world requires a sense of stratification, both ontological and epistemological. The principles of Newtonian mechanics, involving the movement of solid objects, cannot be applied directly to life sciences or to society. Life sciences involve a recognition of how organisms interact with environments, how organisms develop based on species-specific and individual genetic directions, how metabolic processes become self-sustaining in appropriate environments, and so on. Rose argues that it is in the nature of living systems to be radically indeterminate, to continually construct their - our - own futures, albeit in circumstances not of our own choosing' (p7). Thus, emergence is intrinsic to living organisms, which combine change with persistence, and mathematics is generally inadequate to model this. 'Equilibrium mathematics deals with closed systems... but living systems are not sealed off in this way.' (p162)

There is, as Archer (1995:34) argues, an association between empiricism and individualism: empiricist methods favour individualism, or at least the activities of small groups, because they are directly visible, unlike social structures. Popper, for example, insisted that 'all social phenomena, 
and especially the functioning of social institutions, should be understood as resulting from the decisions, actions, attitudes etc. of human individuals' (1945:98). Crucially, reducing the social world to the actions and decisions of individuals or aggregates of individuals amounts to a failure to see how social structures, albeit often not directly visible, are causally efficacious. Reductionism, in this case, fails to understand how rules (even when tacit) regulate conduct, how roles predate their incumbents, that role relationships give rise to 'emergent powers' which 'cannot be reduced to those of their constituents' (Archer 1995:43-51). For all the efforts of positivists and ethnomethodologists, it is difficult to stick with the belief that 'army is just the plural of soldier and all statements about the army can be reduced to statements about the particular soldiers comprising it' (Jarvie 1959:57, cited Bhaskar 2011:70).

Structures, on the other hand, cannot be regarded as fixed. They interact to generate complex historical change. Consider for example the powerful combination of freedom to buy and sell land, enclosures, mercantile imperial expansion, industrial technologies, which led to the powerful industrial capitalism shaping society and culture in 19th Century Western Europe. This in turn led to neo-imperialism, computer technologies, globalisation, finance capital, and so on, but not in a linear process; it resulted in a transformation rather than abolition of capitalism not abolishing it. All these forces have deeply affected modern education, creating the circumstances for economic and political formations (significantly neoliberalism) to shape new forms of school governance, datafication, increasing pressures on childhood, an economistic curriculum... but never absolutely determining what will result:

People... are capable of resisting, repudiating, suspending or circumventing structural and cultural tendencies, in ways which are unpredictable because of their creative powers as human beings. In other words, the exercise of socio-cultural powers is dependent inter alia upon their reception and realization by people: their effect is not direct but mediated, for there are no other ways in which it could be exercised. (Archer 1995:195)

Collective agency is an unpredictable force. As Apple (1984:251) argues, it is reductionist to assume that the education system and its activities can 'be directly read off the economy... a correspondence theory can in no way do justice to the complexity of... school life'.

Social powers do not have to be physical structures (eg bureaucracies, division of labour) but can also be cultural norms of expected behaviour (eg new public management, school choice) or systems of meaning (discourses). Systems of meaning can condition behaviour as much as physical structures do, and hegemonic discourses play an important role in maintaining unequal structures. They are not, however, deterministic.

This inevitably raises concerns about the role and limitations of mathematical representations in 
research. Whilst statistics enables us to map the world and see a stretch of reality at a glance, it is inevitably selective, concealing certain features: it intrinsically tends towards a loss of complexity. This is why we should heed Rose's warning, speaking as a biologist:

Not everything is capable of being captured in a mathematical formula. Some properties of living systems are not quantifiable, and attempts to put numbers on them produce only mystification. (2005:9)

The complex dynamics of emergence and stratification of powers in open systems present multiple challenges to social science, making diverse variants of reductionism a constant threat, as scientific methodologies are applied which do not measure up to the ontological complexity.

Finally, of course, emergence is central to the field of education: indeed emergence is precisely what education is about. Consequently it is rare that children are equally talented in all areas, which is somewhat inconvenient for advocates of unitary intelligence. It means that children rarely progress in smooth linear ways, which radically undermines the mechanics of test-based accountability systems. Further implications of critical realism for education will be discussed later.

\section{Reductionism in the education field: pedagogy and the learner}

The history of 20th Century pedagogical theory can be written as a struggle against reductionism, and which was seminal in its two leading figures Dewey and Vygotsky. Reich and colleagues (2016:102)) summarise Dewey's contribution as 'constant struggle against behaviourism and instrumental reductionism... insistence on context' with behaviourism guilty of forgetting 'emotional, social and cognitive aspects of experience'. Bringing the argument up to date, these authors speculate on Dewey's reaction to contemporary versions of reduction 'for example, in neurscience where the mind is reduced to the brain' (103).

Vygotsky first made his mark with a direct challenge to Pavlovian behaviourism (known at the time as reflexology) in a speech at the Second All-Russian Congress of Psychoneurologists in 1924. The clearest statement of his position appeared the following year in Consciousness as a problem of the psychology of behaviour (Vygotsky 1925), an exemplary critique of the reductionism of this crude materialism which ignored consciousness and was overreliant on the stimulus-response reflex (S$\mathrm{R})$.

Within several pages, Vygotsky has challenged the 'reflexologists' for:

- failing to distinguish between human and animal behaviour;

- inappropriately using physiology to explain psychology;

- refusing to think about consciousness or language; 
- $\quad$ assuming that observable behaviours are sufficient for building a theory;

- a neglect of historical and social dimensions.

Some brief quotations will show the power of this critique:

Any principal distinction between animal behaviour and human behaviour is obliterated. Biology devours sociology and physiology devours psychology. Human behaviour is studied as the behaviour of a mammal. What is essentially new, what consciousness and psyche brings in human behaviour, is ignored. $(\$ 1.3)$

By ignoring the problem of consciousness psychology has deprived itself of access to the study of some rather complex problems of human behaviour. It is forced to restrict itself to explaining no more than the most elementary connections between a living being and the world. $(\$ 1.1)$

Far from aligning with Marxism, as its advocates assumed (Kozulin 2005), this reductionist version of materialism lacks any emancipatory potential. The reflexologists had failed to grasp the most basic difference between human beings and animals:

Whereas animals passively adapt to the environment, man actively adapts the environment to himself... The spider that weaves his web and the bee that builds his cell out of wax do this out of instinct, mechanically, always in the same way, and in doing so they never display any more activity than in any other adaptive reactions. But the situation is different with a weaver or an architect. As Marx said, they first built their works in their heads; the result of their labours existed before this labour in ideal form. (§2)

There is no room for imagination and creativity in the behaviourist vision of human learning. Following a precise imminent critique, Vygotsky moves on to look at humanity from other perspectives. He points to three key advantages of human learning: 'historical experience, social experience, and doubled experience'(§2).

All our life, our labour and behaviour draw broadly on the experience of former generations, which is not transmitted at birth from father to son. We may provisionally designate this as a historical experience...

If I know the Sahara and Mars although I have never travelled outside my country and have never looked into a telescope, obviously the origin of this experience is due to the experience of other people who have travelled to the Sahara and have looked into a telescope... Let us call this the social component of our behaviour... 
Citing Marx's famous reference to spiders and weavers, bees and architects, he explains 'doubled experience' in terms of labour repeating

what had already been done beforehand in the worker's imagination... It is this doubled experience that enables man to develop forms of active adaptation that do not exist in animals. $(\S 2)$

This is why play is so important: it is crucially an occasion for the emergence of new meanings (Vygotsky 1978:92-104). The current 'schoolification' of early years education in England (Bradbury 2018) erodes the foundations of expansive learning.

As Blunden deduces, reductionist psychology not only results in very limited understanding, it debases our humanity by disempowering us:

The aim of controlling human behavior answers to the needs of capitalist, prison guard, interrogator, marketer, politician and bureaucrat, but an emancipatory psychology aims to free people from manipulation so that they can have voluntary control over their own behaviour. (Blunden 2012:127)

He singles out four key features of behaviourism:

1) its aim is the prediction and control of people's behaviour

2) it excludes the use of evidence offered by the experimental subject

3) it excludes the notion of consciousness, and

4) it is a part of natural science, dealing with human beings as uncultured animals. (ibid) Furthermore, in concluding his speech to the 1924 Congress, Vygotsky anticipates the Critical Realist argument that we need to go beyond the immediately visible in order to understand the deeper forces at work.

We should not forget that there are whole sciences that cannot study their subject through direct observation! The historian and the geologist reconstruct the facts (which already do not exist) indirectly... Similarly, the psychologist is often in the position of the historian and the geologist. Then he acts like a detective who brings to light a crime he never witnessed. (Vygotsky 1926)

Bringing this up to date, Bakhurst (1997:156) reminds us that behaviourism is only one of two major forms of psychological reductionism: the other is 'physicalism', i.e. the 'attempt to analyse mental states in terms of brain states, arguing that the mind is just the working brain'. If behaviourism lives on in educational practice in attempts to teach literacy exclusively as phonic correspondences, drawing on stimulus-response techniques, 'physicalism' can be found in 
fashionable appeals to 'brain-based learning' and the belief that brain scans provide an adequate description of thinking. Contrary to this, Vygotsky's insistence on the connectedness of the individual mind with culture, history and society, and the pivotal importance of active meaningmaking through speech and other sign systems, lays the basis for a wide array of pedagogies which are not limited to the acquisition of pre-established facts: dialogic, place-based, investigative, dramatic, problem-solving, and so on.

\section{Reductionist misunderstandings of poverty-related underachievement}

There are many reductionist pitfalls in theorising the relationship between poverty and schooling. An adequate understanding requires bringing together different forms of knowledge (sociology and urban geography, curriculum and pedagogy, organisational theory etc), and drawing on appropriate disciplinary paradigms for examining a stratified, conflictual and open situation. For example, sociological analysis might range from statistical correlations to youth and classroom ethnography. Recent years have seen some outstanding research on inequality (eg Dorling 2014; Pickett and Wilkinson 2010) revealing acute polarisation of income and ownership. The insights are important but it does not identify the underlying causes. For this a systemic understanding of the dynamics of finance capital and neoliberal globalisation are needed, including the mechanisms of exploitation and accumulation by dispossession (see Harvey 2005; 2017).

The same problem arises with Standing's (2011) widely accepted notion of 'precariat'. Leaning towards the deficit 'underclass' theories (Murray 1996) which underpin derogatory 'poverty porn' accounts of working class life, this concept misses the point that wage workers (Marx's original definition of proletariat) are inherently precarious, given that their position in the economic system is defined by not owning the means of production and therefore depending for work on the small minority who do. This intrinsic precarity is exaggerated by the economic powers of globalised capital, and the diminished power of workers in societies defined by neoliberalism. Precarity is not simply the condition of a distinct social group of unskilled, unemployed or marginally employed, but increasingly affects large sections of population, including many employees with good qualifications and in white-collar or professional work.

This understanding, however, requires a theoretical understanding of class which does not rely on surface appearances such as lifestyle (as with Savage 2015). Even in Marx's time:

the largest group of wage labourers was not the industrial working class but domestic servants, most of whom were female. The working class, then, is not always male, brawny and handy with a sledgehammer. (Eagleton 2011:171) 
An understanding of the educational impact of poverty requires stratification. The concept of class is rooted in economics, and it is exploitation and dispossession rather than cultural reproduction that generates poverty - people are poor because of exploitative work conditions not the bad habits of underclass parents. At the same time we have to recognise the interactions between economics, culture and psychology, without allowing culture or psychology to b (X 2013; Y\&X 2013). To recognise the major influence of parents' qualifications on children's attainment (Sammons et al 2008 ) is not to deny economics, but to recognise the cultural means by which economic advantage transmits between generations (Bourdieu and Passeron 1990).

Reductionist understandings of the link between social position and educational achievement take many forms, but crucially omit key layers and causal forces. For example, blaming teachers for low attainment fails to take seriously the economic, cultural and psychological pressures. Conversely theories of genetically inherited intelligence represent a reduction of psychological to biological explanations. The 'lack of aspiration' argument, and the demand for greater personal 'resilience', shifts the burden to individualistic psychological explanations, forgetting that it is difficult to sustain high aspirations without corresponding opportunities. The Conservative reframing of social justice as 'social mobility' within an assumed meritocracy (Littler 2018) is a denial of structure and inflation of individual potentiality.

Much of the statistical data generated to track the link between poverty and education is short on theory, and whilst acknowledging that correlation is not causality, the texts are full of casual conclusions that 'X causes Y' (Gorard and See 2013:22). Further, important distinctions which would allow the complex realities to speak through the data are often missing, as with the overuse of free school meal entitlement (FSM) as a proxy indicator of poverty. The simple binary FSM / notFSM does not reflect the intense multiple deprivation experienced by young people in deindustrialised areas or run-down coastal towns. The absence of FSM entitlement covers everything from extreme affluence and privilege to being seriously poor but unable to meet the official FSM criteria. The FSM category does not reflect unhealthy housing conditions, low levels of parental qualifications or occupations, or the fatalism and disillusionment which results from growing up in a deindustrialised region. Even complex multiple regression analysis can only deal with averages and suggest tendencies, and does not cope well with tracing paths of influence. The mathematics of tendencies and effects, which is at basis additive / subtractive, cannot reflect the possibility that a combination of influences, including adverse childhood experiences (ACEs), can create a tipping point.

A non-reductionist attempt to 'close the gap' must look beyond as well as within the school. This would surely involve preventing child poverty, free activity schemes in school holidays, looking at 
how teachers understand the lives of the communities they serve, and so on. To theorise this requires bringing together different sub-disciplines of education, and sociology on a macro-, mesoand micro-level. It also requires considering such organisational / pedagogical factors as segregation by 'ability', the impact of high-stakes accountability on teacher recruitment, or the need to enrich young people's experience.

\section{Reductionist theories of school development}

School evaluation and development are understood in many countries through paradigms of School Effectiveness (SE) and School Improvement (SI). Recurrent keywords such as accountability, effectiveness and leadership work ideologically by emphasising technical rationalism, eclipsing questions of political or moral purpose.

School Effectiveness is a quantitative paradigm which calculates the relative impact of a school on student learning, and then attempts to identify what has brought that about. Endemic is:

- $\quad$ a methodological reductionism (e.g. mechanistic causality, including the assumption of linear cause-and-effect relationships);

- contextual reductionism (a failure to examine environmental influences when tracing causal relationships internal to a school).

Methodological reductionism is exemplified by assumptions of simple linear pathways of influence, as inputs lead to higher test scores; whereas in reality key factors can operate recursively, events operate as catalysts, forces contradict each other or fail to actualise due to adverse context - indeed all the complex possibilities understood by critical realism (see earlier). Contextual reductionism includes the tendency of neoliberal accountability systems to treat schools as isolated entities, disconnected from pupils' lifeworlds beyond school, youth culture, commercial influences or indeed the effects of the national education system.

The harnessing of School Improvement theory to School Effectiveness reinforced teleological reductionism, by privileging attainment data as the only important aim of education. Keywords such as vision, mission and values are not only hollowed out terms, they are a kind of spiritual or vitalist add-on which disguises the values reductionism of the post-1990 SI paradigm. The previous emphasis on willing thoughtful participation, whilst surviving as rhetoric, was replaced by topdown power relationships of a system defined by surveillance and control (X 2004; Gunter 2001; Hargreaves 1994). There is no concession that some innovations are ill-conceived, that professionals have a right and duty to question them, or that some changes should be resisted. Causation is poorly conceptualised by SE's list of 'key characteristics', which reify potentially significant activities, concerns and interaction, and are in any case too vague and ambiguous to be 
helpful. What, for example, does 'a focus on teaching and learning' mean? It could be anything from transmission of Hirschian lists of facts (Hirsch 1987) to place-based discovery methods. An emphasis on assessment might mean anything from authentic assessment or Assessment for Learning to high-stakes testing: to see all of this as beneficial forgets the collateral damage which high-stakes accountability entails.

Another major keyword is culture, potentially a very powerful concept because it bridges between material and spiritual: culture is matter which means something, as when an artist reshapes material to convey a meaning. This complex concept has been reduced from a powerful tool for examining patterns of life and their inherent value to a means of domestication and control. This is exemplified in Deal and Peterson's (1999) argument that the headteacher's role is 'to manage culture'.

An alternative non-reductive understanding of school culture would recognise the inequalities of power and the dynamic interrelation of school world and lifeworld, enabling a conversation about how some schools are able to moderate the impact of disadvantage. This might involve, for example:

- examining the cultural messages of classrooms which are dominated by the teacher's voice, closed questions and rituals of transmission of superior wisdom;

- developing a better understanding of cultural difference in order to prevent high levels of exclusion;

- understanding how tacit assumptions about 'ability' and 'intelligence' are worked out in classroom interactions;

- discovering how tacit assumptions about single parents and 'dysfunctional' working-class families operate symbolically in classroom interactions. (X, 2003: 36-7)

An empowerment culture which enables marginalised young people to develop as learners and members of society might involve, for example, teamwork in planning social-constructive and coooperative learning; curriculum which connects with students' lives while building towards powerful academic knowledge; a school ethos which enable learners to find a voice; and a counterculture to the despair of an impoverished or oppressed community.

Using culture in this sense would avoid reductionism: it does not neglect power, difference, privilege, barriers of communication, differences of perspective, or the links between practices and (explicit or tacit) theories. It remains open to contradictions and tensions within the school, and between the school and the outside world (see Alvesson 2002),

The naively positive developmental models of change used in mainstream School Improvement are reductionist simplifications. Schools require a better understanding of open systems, and could even 
learn from the science of living things, in order to reference openness, scale, stratification, complexity, systemic pressures and human purpose. One alternative would be to emulate (but not just copy) ecological models:

- The evolution of living systems is self-organising and dynamic (i.e. not simply the result of causes, but of a long and accident-prone learning history on the system-environment border).

- Developments can only be sustained if they have an equilibrium between innovation, verification and preservation.

- Development takes place through exchange effects, more exactly, through the synchronisation of processes on the macro and micro levels. (Schools must connect effects on a personal and social plane. School development involves personal, social and organisational learning.)

- The evolution comes about through a reciprocal interplay of biological psychic and social development actions. (Learning processes are necessarily holistic - head, heart and hand. If you ignore this, you end up with medium- and long-term damage to personal development.) (Büeler 1998: 675, summarised in X 2003:26)

Increasingly school development is seen in terms of leadership, which, despite variants such as 'distributed leadership', invariably defaults to individualised top-down surveillance and control. A rare alternative is Wilkinson and Kemmis's (2014) variation on actor network theory (Latour 2005), which recognises the agency of non-humans but without losing the sense of agency due to participants' interpretations and intentions. Following Schatzki (2002), its focus is on how 'practice architectures' bring together 'sayings, doings and relatings' which are 'not split off from one another' but 'hang together' in the overall project of a practice (Kemmis et al 2012:35). These fit within wider arrangements: cultural-discursive, material-economic and social-political preconditions that make practices possible. Thus for example what is said within the school is shaped by the discourses of the wider society and its views of childhood and education. Such a model avoids the default individualism and apolitical neglect of structural power inequality, and the marginal recognition of material structural powers, which characterise the majority of 'leadership' thinking.

\section{The reductionist assumptions of 'evidence-based teaching'}

The methodology of 'evidence-based teaching' (X 2018) - RCTs aggregated through meta-analyses, then further amalgamated and compared through what we might call 'meta-meta-analyses' or 'megasynthesis' (Hattie 2009 or the Education Endowment Foundation's Toolkit) - is exemplary of reductionism in its many forms. There have been powerful challenges to the statistical assumptions 
(Simpson 2017; 2018; Lilley 2018) but here I will briefly highlight a few arguments which connect with issues of reductionism. (See X 2018 for more detailed explanation and illustration.)

Firstly, the call for Education to imitate Medicine fails to recognise the specifics of particular fields and sciences, and loses the complexity and specificity of situations. Its tacit - and mistaken assumptions are that medical research consists entirely of drugs trials, that the clinical judgement of the doctor has become marginal, that there is an easy transfer from findings of drugs trials to individual diagnosis and treatment, that double-blind trials are possible in education, and that theory is unimportant. Fundamental assumptions of drugs trials are impossible in teaching, including double blinding and 'placebo': what exactly should your 'control group' be doing - a deliberate avoidance of the behaviour under investigation or 'business as usual'? Imagine the simple case of an RCT about the benefit of more open questions: should the control group experience only closed questions, or should the teacher simply be asked to do as s/he normally does and not think too much about the type of question? As Pawson states:

This is not the world in repose. This is no vacuum... Control groups or control areas are in fact kept very busy. (Pawson 2006:51)

With regard to theory, Pawson reminds us that:

Medical treatments... are the embodiment of years of theory-testing. They are already scientific inquiry incarnate before the first Phase III RCT is even designed. By this stage, medical science knows pretty well how a treatment works and it entrusts to the RCT a slightly different question about how well it works in a particular manifestation. (Pawson 2006:47)

By contrast, RCTs in education are frequently lacking in theoretical awareness, and 'treatments' applied and evaluated with no attempt to ask why and how they works, in what circumstances, and what barriers must be overcome. In other words, the underlying mechanism, structure or force is not discussed.

This reflects the empiricist assumption that the closed situation of experiments sufficiently explains what happens in real-world open systems. As Critical Realists explain, experiments are not a reflection of reality, and the data does not simply speak for itself.

That is only the start of the problem. I will highlight some further simplifications here.

i) Data analysis frequently relies on the reductionist assumption of fairly regular and reliable linear progress. This is no longer tenable in accountability data (see analysis from Education Datalab 2015). 
ii) Episodes of teaching are not simply 'interventions', but involve dynamic interaction between teacher and class which have a path of development, a history, and because they are semiotic rather than mechanical, mutual misunderstanding is endemic .

iii) The classic RCT tries to eliminate the human factor because 'human volition is seen as a contaminator' (Pawson 2006:27), whereas social change is brought about through the human agent.

iv) For all the attempts of system managers to engineer a uniform and standardised system, classrooms remain 'open systems' which are ultimately unpredictable. Classroom situations are also recursive: what the teacher does on one day affects pupils' expectations and interpretations the next.

As the higher levels of meta-analysis and mega-synthesis are reached, complexity is progressively buried. Feinstein (1995) argued that 'Important inconsistencies are ignored and buried in the statistical slurry'. Gene Glass, who originated the idea of 'meta-analysis', has subsequently issued this sharp warning about heterogeneity:

Our biggest challenge is to tame the wild variation in our findings not by decreeing this or that set of standard protocols but by describing and accounting for the variability in our findings. The result of a meta-analysis should never be an average; it should be a graph (cited Robinson 2004:29, my italics).

Despite this, the biggest and most prominent 'meta-meta-analysis' in English schooling, the EEF Toolkit, systematically ignores the 'apples and oranges' problem. Hattie's work too is guilty of throwing into the mixing bowl quite incompatible behaviours simply because they are referred to by a similar name ('feedback', for example). (X 2018; Lilley 2017]

\section{Final remarks}

This paper has examined multiple forms of reductionism, including the deep shortcomings of an empiricist philosophy of natural and social science. This is not to undermine ontological realism or the need to empirically verify or exemplify ideas, but to insist on stronger foundations and methodologies. It has argued the need to attend to openness, stratification and emergence. The reductionist problems highlighted here have deep historical roots. Because modern science began with Galilean and Newtonian mechanics, its principles are often assumed to apply across the board including life sciences and indeed social fields. This can be seen in Tom Bennett's (2013) populist diatribe against 'non-scientific' research in education, and the accusation that research which does not emulate lab experiments is quackery.

Stephen Rose has referred to the 'physics envy' of many biologists. We are faced with something like 'engineering envy' among many educational statisticians and policy makers desperate for 
efficiency and certainty. This accompanies an increasing faith that neuroscience and behavioural genetics will open the window to understanding cognition.

Biesta (2010:496) presents the case that, in education, we are dealing with open, recursive, semiotic systems:

- open because they interact with their environment and do not operate deterministically;

- recursive between they 'feed back into themselves, so that the behaviour of the system is the result of a combination of external factors and internal dynamics'

- semiotic because they 'do not operate through physical force but through the exchange of meaning'.

Even this is too straightforward. In formal education, we are actually dealing with multiple nested and interlocking systems (the individual learner, groups, classrooms, the accountability machine) and various forms of interaction and interface (teacher-pupil, teachers-management, schoolparents). Learners are pulled between schoolworld and lifeworld - particularly challenging if there is a distance between school and community cultures. Even a solo act of learning involves interaction between subject and object, mediated by various instruments and cultural tools', in a dance involving backwards and forwards motion between abstract concepts and sensory experience. And this is not even to begin considering social, economic and cultural power differences or the politics of curriculum.

Education is fundamentally about emergence, which operates at the various interfaces mentioned above. The quest for certainty and efficiency, though probably inevitable for formal schooling (Biesta 2015), is unattainable and undesirable if taken too far. Education (Bildung, pedagogy) turns into its opposite, a machine for the transmission of official dogma, received opinion and hegemonic beliefs. 


\section{References}

Alvesson, M. (2002). Understanding organizational culture. London: Sage.

Apple, M (1984) Against reductionism (essay review). History of Education Quarterly 24(2)

Archer, M (1995) Realist social theory: the morphogenetic approach. Cambridge: Cambridge University Press

Bakhurst, D (1997) Activity, consciousness, and communication. In M Cole, Y Engeström and O Vasquez (eds) Mind, culture and activity: Seminal papers from the Laboratory of Comparative Human Cognition. Cambridge: Cambridge University Press

Beck, J (2007) Education and the middle classes: Against reductionism in educational theory and research. British Journal of Educational Studies 55(1)

Bennett, T (2013) Teacher proof: why research in education doesn't always mean what it claims, and what you can do about it. London: Routledge

Bhaskar, R (1978) A realist theory of science. Hassocks: Harvester Press

Bhaskar, R (1979) The possibility of naturalism: A philosophical critique of the contemporary human sciences. London: Routledge

Bhaskar, R (2011) Reclaiming reality: A critical introduction to contemporary philosophy. London: Routledge

Biesta, G (2010) Why 'what works' still won't work: From evidence-based education to value-based education. Studies in the Philosophy of Education 29, 491-503

Biesta, G (2015) Improving education through research? From effectiveness, causality and technology to purpose, complexity and culture. Policy Futures in Education, 14(2), 194-210

Blunden, A (2012) An interdisciplinary theory of activity. Leiden: Brill

Bock,, I and Goode, J eds (1998) The limits of reductionism in biology. Chichester: John Wiley

Bourdieu, P (1977) Outline of a theory of practice. Cambridge: Cambridge University Press

Bourdieu, P and Passeron, J-C (1990) Reproduction in education, society and culture (second edition). London: Sage

Bourdieu, P and Passeron, J-C (1990) Reproduction in education, society and culture (second edition). London: Sage

Bradbury, A (2018) Datafied at four: The role of data in the 'schoolification' of early childhood education in England. Learning, Media and Technology (online)

Büeler, X (1998) Schulqualität und Schulwirksamkeit. In H Altrichter et al (eds) Handbuch zur Schulentwicklung. Innsbruck: StudienVerlag

Clarke, M (2012) The (absent) politics of neo-liberal education policy. Critical Studies in Education 53(3), pp297-310

Deal, T and Peterson, K (1999) Shaping school culture. San Francisco: Wiley

Dennett. D (1995) "Darwin's Dangerous Idea." The Sciences 35(3), pp34-40

Dorling, D (2014) Inequality and the 1\%. London: Verso

Feinstein, A (1995) Meta-analysis: Statistical alchemy for the 21st Century. Journal of Clinical Epidemiology 48(1), 71-9

Eagleton, T. (2011) Why Marx was right. New Haven: Yale University Press 
Education Datalab (2015) Seven things you might not know about our schools.

http://www.educationdatalab.org.uk/getattachment/Blog/March-2015/Seven-things-you-might-notknow-about-our-schools/EduDataLab-7things.pdf.aspx

Engels, F (1964) Dialectics of nature (3rd revised edition). Moscow: Progress Publishers

Feinstein, A (1995) Meta-analysis: Statistical alchemy for the 21st Century. Journal of Clinical Epidemiology 48(1), 71-9

Flyvbjerg, B (2001) Making social science matter: why social inquiry fails and how it can succeed again. Cambridge: Cambridge University Press

Gorard, S and See, B (2013) Overcoming disadvantage in education. London: Routledge

Gunter, H (2001) Leaders and leadership in education. London: Chapman

Hargreaves, A (1994) Changing teachers, changing times: Teachers' work and culture in the postmodern age. New York: Teachers College Press

Harvey, D (2005) A brief history of neoliberalism. Oxford: Oxford University Press

Harvey, D (2010) The enigma of capital and the crises of capitalism. London: Profile Books

Harvey, D (2017) Marx, capital and the madness of economic reason. London: Profile Books

Hattie, J (2009) Visible learning: A synthesis of over 800 meta-analyses relating to achievement.

London: Routledge

Hirsch, E (1987) Cultural literacy: What every American needs to know. Boston MA: Houghton Mifflin

Kemmis, S., Edwards-Groves, C., Wilkinson, J., \& Hardy, I. (2012). Ecologies of practices. In P. Hager, A. Lee, \& A. Reich (Eds.), Practice, learning and change (pp. 33-49). Dordrecht: Springer.

Kozulin, A (2005) The concept of activity in Soviet psychology: Vygotsky, his discplines and critics. In H Daniels (ed) An introduction to Vygotsky (2nd edition) London: Routledge

Latour, (2005) Reassembling the social: An introduction to actor-network theory. Oxford: Oxford University Press

Littler, J (2018) Against meritocracy: culture, power and myths of mobility. London: Routledge

Lukes, S (1968) Methodological individualism reconsidered. British Journal of Sociology, 19(2).

Murray, C (1996) The emerging British underclass. London: Institute of Economic Affairs

Lilley, G (2017) Feedback. visablelearning.blogspot.com/p/feedback.html (accessed 7.1.19)

Lilley, G (2018) Effect size. visablelearning.blogspot.com/p/effect-size.html (accessed 7.1.19)

Pawson, R (2006) Evidence-based policy: A realist perspective. London: SAGE

Pickett, J and Wilkinson, R (2010) The spirit level: why equality is better for everyone. London: Penguin

Popper, K (1945) The open society and its enemies (4th edition). London: Routledge

Prigogine, I and Stengers, I (2017) Order out of chaos: man's new dialogue with nature (revised edition). London: Verso

Reich, K, Garrison, J and Neubert, S (2016) Complexity and reductionism in educational philosophy: John Dewey's critical approach in 'Democracy and Education'. Educational philosophy and theory 48(10)

Robinson, D (2004) An interview with Gene V Glass. Educational Researcher, 33(3), 26-30

Rose, S (2005) Lifelines: life beyond the gene (revised edition). London: Vintage 
Rose, S and Rose, H (1976) The politics of neurobiology: biologism in the service of the state. In H Rose and S Rose (eds) The political economy of science: ideology of/in the natural sciences (pp 96111). London: Macmillan

Sammons $\mathrm{P}$ et al (2008) Influences on children's attainment and progress in Key Stage 2: cognitive outcomes in Year 6. EPPE 3-11 project, DCSF Research Report DCSF-RR048

Savage, M (2015) Social class in the 21st century. London: Pelican

Sayer, A (2000) Realism and social science. London: Sage

Sayer, A (2010) Reductionism in social science. In R Lee (ed) Questioning Nineteenth-Century assumptions about knowledge: II Reductionism (pp 5-39). New York: SUNY Press

Schatzki, T. (2002). The site of the social: A philosophical account of the constitution of social life and change. University Park, PA: University of Pennsylvania Press.

Shapiro, S (1990) Between capitalism and democracy: Education policy and the crisis of the welfare state. New York: Bergin and Garvey

Simpson, A. (2017). The misdirection of public policy: Comparing and combining standardised effect sizes. Journal of Education Policy, 32(4), 450-466

Simpson, A (2018) Princesses are bigger than elephants: Effect size as a category error in evidencebased education. British Educational Research Journal 44(5)

Y\&X (2013) XXX

Standing, G (2011) The precariat: The new dangerous class. London: Bloomsbury

Vygotsky, L (1925) Consciousness as a problem in the psychology of behavior (transl. N Veresov) https://www.marxists.org/archive/vygotsky/works/1925/consciousness.htm

Vygotsky, L (1926) The methods of reflexological and psychological investigation https://www.marxists.org/archive/vygotsky/works/1925/reflexology.htm

Vygotsky, L (1978) Mind in society. Cambridge, MA: Harvard University Press

$\mathrm{X}(2003) X X X$

X (2004) XXX

X (2013a) XXX

X (2013b) XXX

X (2018) XXX 